\title{
Estudo morfométrico e estereológico do gânglio celíaco em cães sadios
}

Wanderley Lima GUIDI ${ }^{1}$ Emerson Ticona FIORETTO ${ }^{1}$ Antonio Augusto Coppi Maciel RIBEIRO'

\section{Correspondência para:}

WANDERLEY LIMA GUIDI

Departamento de Cirurgia

Faculdade de Medicina Veterinária e Zootecnia

Universidade de São Paulo

Avenida Prof. Dr. Orlando Marques de Paiva, 87

05508-270 - São Paulo-SP

wanderleyguidi@hotmail.com

Recebido para publicação: 18/06/2004 Aprovado para publicação: 21/09/2005

1- Departamento de Cirurgia da Faculdade de Medicina Veterinária e

Zootecnia da Universidade de São Paulo, São Paulo - SP

\section{Resumo}

Palavras-chave:

Gânglio.

Morfometria.

Nesta pesquisa o aspecto macroestrutural, microestrutural e histoquímico foram investigados em 6 cães clinicamente saudáveis para identificar a possível alteração na estrutura, morfométrica e parâmetros quantitativos de neurônios do complexo ganglionar celíaco. Nossa observação revela que o gânglio celíaco foi originado da origem da artéria celíaca e mostra um aspecto irregular sendo caracterizado como um complexo. Histoquimicamente, neurônios NADPH diaforase reativos foram identificados. Esta reação positiva, em animais saudáveis, permite-nos concluir que estes neurônios eram potencialmente nitrergicos, contudo, para confirmar o aspecto nitrergico para estes neurônios ele é necessário combinar métodos imunohistoquimicos.

\section{Introdução}

O sistema nervoso autônomo, está organizado em grupos de gânglios que são divididos esquematicamente em para vertebrais, pré-vertebrais, para viscerais e intramurais. Os gânglios pré-vertebrais estão em sua maioria dispostos em amplos plexos nervosos, o plexo abdominal inclui o gânglio celíaco e o gânglio mesentérico superior localizados próximos à aorta ${ }^{1}$

Os gânglios celíaco e mesentérico cranial, em alguns casos, formam uma única massa difusa situada na parede dorsal da cavidade abdominal ao nível da primeira vértebra lombar ${ }^{2}$.

O termo "cérebro abdominal" para o gânglio celíaco devido a sua complexa função foi utilizado ${ }^{3}$. Relacionaram-se um acúmulo de neurônios esplênicos no gânglio celíaco do gato através da implantação de neurotraçador ${ }^{4}$. Sendo um componente do complexo ganglionar celíaco mesentérico cranial, definiu-se que o gânglio mesentérico cranial é um centro de integração dos reflexos gastrintestinais, entretanto detalhes de sua estrutura permanecem obscuros devido à escassez de informações 5 .

Apesar dos esforços investigativos nesta área em animais de laboratório, muito pouco ainda se sabe a respeito sobre o gânglio celíaco em grandes mamíferos como o cão. Neste trabalho, propomos a investigação de animais clinicamente sadios no que tange as características microestruturais e a expressão de NADPHdiaphorese no gânglio celíaco a fim de fornecer subsídios para o entendimento de neuropatias que acometem o sistema nervoso visceral.

\section{Materiais e Métodos}

No decorrer deste estudo foram utilizados seis gânglios celíacos esquerdos provenientes de cães domésticos (Canis familiares) adultos, fêmeas, sem raça definida (SRD). Os animais foram obtidos no Hospital Veterinário da Faculdade de Medicina Veterinária e Zootecnia da Universidade de São Paulo (HOVETFMVZ-USP). Os cães utilizados nesta investigação apresentaram ficha clínica de onde foram retirados dados essenciais tais como: idade, peso. Desta forma, os animais tinham idades variando entre 8 a 12 anos. $O$ peso dos animais variou de 11 a $15 \mathrm{Kg}$ (média de13,3 Kg). Os animais foram então 
subdivididos, em1A e 1B. Três gânglios celíacos esquerdos (em cada subgrupo), sendo o subgrupo1A para morfometria e microscopia de luz de cortes semi-finos, e o subgrupo 1B para estudo histoquímico visando identificar os neurônios com atividade NADPH-diaphorase (positivos para NADPH-d).

\section{Colheita do Material}

Para a coleta do gânglio celíaco esquerdo, foi realizada uma celiotomia mediana pré-retro-umbilical. A pele e a musculatura foram rebatidas para permitir amplo acesso à cavidade abdominal. Posteriormente, foi feito o deslocamento caudo-ventral das vísceras permitindo a visualização das artérias celíaca e mesentérica cranial, onde o gânglio se encontra sobreposto e lateralmente a estas, e a identificação da glândula adrenal esquerda, a qual referenda a posição do gânglio. Após a identificação do gânglio celíaco esquerdo, a aorta abdominal foi canalizada caudalmente a emergência da artéria mesentérica cranial, perfundida com solução de lavagem composta de salina tamponada fosfatada (phosphate buffered saline) (PBS) (0.1M; pH 7.4) $\left(\mathrm{SYNTH}^{\circledR}\right)$ e heparina a $2 \%$ $\left(\mathrm{ROCHE}^{\circledR}\right)$.

\section{Fixação e processamento do material para estudo morfométrico à microscopia de luz de cortes semi- finos \\ Após a lavagem do sistema} (conforme descrito anteriormente), uma solução fixadora de Karnovsky modificada composta de glutaraldeído 5\% $\left(\mathrm{MERCK}^{\circledR}\right)$ e formoldeído $1 \%\left(\mathrm{SYNTH}^{\circledR}\right)$ em tampão cacodilato de sódio $\left(\mathrm{EMS}^{\circledR}\right)(0,125 \mathrm{M} ; \mathrm{pH}$ 7.4) foi perfundida pela aorta abdominal, permitindo a fixação do material "in situ" para a posterior retirada do gânglio para prosseguir a fixação do material por imersão conforme descrito a seguir.

Depois de retirado, o gânglio foi cortado crânio-caudalmente em pequenos fragmentos (1-2mm) e imerso na mesma solução fixadora por $2-3$ dias a $4^{\circ} \mathrm{C}$.
Posteriormente, os fragmentos foram lavados em solução tampão cacodilato de sódio $\left(\mathrm{EMS}^{\circledR}\right)$ e pós-fixados em solução de tetróxido de ósmio a $2 \%\left(\mathrm{EMS}^{\circledR}\right)$ durante 90 minutos sob agitação moderada e constante e no escuro a temperatura ambiente. Em seguida, foram lavados novamente em tampão cacodilato de sódio $\left(\right.$ EMS $\left.^{\circledR}\right)$ e após foram lavados em água destilada e contrastados em bloco com solução aquosa de acetato de uranila $\left(\mathrm{EMS}^{\circledR}\right)$ durante 90 minutos sob agitação moderada e constante, no escuro e a temperatura ambiente. A seguir, o material foi lavado em água destilada e desidratado em série crescente de etanol $(50 \%, 70 \%, 90 \%$ por dez minutos cada e $100 \%$ por vinte minutos cada) e óxido de propileno $\left(\mathrm{MERCK}^{\circledR}\right)$ (durante 10 minutos).

Realizada a desidratação, foi feita a embebição do material em solução de óxido de propileno $\left(\mathrm{ALDRICH}^{\circledR}\right)$ e resina araldite (502 Polyscience Inc ${ }^{\circledR}$ ).

Depois, o material foi transferido para resina araldite pura (502 Polyscience Inc $\left.^{\circledR}\right)$, permanecendo por um período de oito horas, sendo posteriormente trocado para uma nova resina pura e permanecendo por mais oito horas, e finalmente o material foi transferido para uma nova resina pura e permaneceu por três dias em estufa a $60^{\circ} \mathrm{C}$. Os blocos foram cortados com o auxílio do ultramicrótomo "Leica ultracut UCT ${ }^{\mathbb{B}}$ " a uma espessura de dois micrometro com navalha de vidro, fornecendo os cortes semi-finos. As seções foram coradas com uma solução de azul de toluidina alcoólica e montadas sobre lâmina com uma gota de araldite como meio de montagem e de visualização. O material assim montado foi observado no microscópio de luz e epi-fluorescência "LEICA DMR ${ }^{\circledR}$ para o estudo morfométrico .

\section{Estudo Histoquímico (Reação da NADPH-hiaphorase)}

Após a lavagem do sistema, foi perfundida uma solução fixadora de formoldeido a 4\% em PBS (0.1M; pH 7.4;) $\left(\mathrm{SIGMA}^{\circledR}\right)$ por meio da aorta abdominal, e a seguir, o gânglio foi retirado e imerso na 
mesma solução fixadora por um período mínimo de duas horas e máximo de 2-3 dias a $4^{\circ} \mathrm{C}$. Depois, este foi transferido para uma solução salina potássica tamponada fosfatada (KPBS) (0,02M, pH 7,4) $\left(\mathrm{SYNTH}^{\mathrm{O}}\right)$ com sacarose $\left(\mathrm{SYNTH}^{\mathrm{O}}\right)$ a $20 \%$, durante 12 horas a $4^{\circ} \mathrm{C}$.

Para a identificação dos neurônios NADPH-diaphorase positivos foi utilizada a técnica proposta pelos autores ${ }^{6,7}$, no qual os gânglios foram seccionados com uma espessura de $30 \mathrm{~mm}$ no micrótomo de congelação LEICA HISTOSLITE $2000^{\circledR}$, sendo o material congelado em gelo seco previamente.

Após o material ser seccionado, foi colocado em uma solução "anti-freezer", composta por PBS $\left(\mathrm{SIGMA}^{\circledR}\right)$, sacarose $\left(\mathrm{SYNTH}^{\circledR}\right)$ e etilenoglicol $\left(\mathrm{SIGMA}^{\circledR}\right)$ e mantido no freezer a $-20^{\circ} \mathrm{C}$ até que todas as amostras fossem coletadas para que as reações fossem feitas ao mesmo tempo.

Posteriormente, as secções foram lavadas três vezes em PBS (SIGMA ${ }^{\circledR}$ ) durante um período de 30 minutos cada, sendo em seguida incubadas em solução composta por b-NADPH $(1 \mathrm{mg} / \mathrm{ml})$ $\left(\mathrm{SIGMA}^{\circledR}\right)$; nitro blue tetrazolium (NBT) (SIGMA $\left.^{\circledR}\right)(0,25 \mathrm{mg} / \mathrm{ml})$ e triton X-100 $\left(\operatorname{SIGMA}^{\circledR}\right)(0,3 \%)$ em solução salina tamponada fosfatada (PBS) por 60 minutos a $37^{\circ} \mathrm{C}$. As reações controle (reações negativas) foram realizadas simultaneamente e sem utilização do b-NADPH (SIGMA $\left.{ }^{\circledR}\right)$ durante o mesmo período de incubação.

\section{Estudo morfométrico geral}

A partir de 33 secções seriadas com dois micrometros de espessura, foram mensurados 47 neurônios por gânglio (total de 141 neurônios) e 36 núcleos neuronais por gânglio (total de 108 núcleos), sendo que os neurônios contidos nas três primeiras e nas três últimas secções foram excluídos, seguindo o mesmo princípio das linhas de inclusão e exclusão, aplicadas no plano tridimensional ${ }^{8,9}$. Áreas testes foram escolhidas aleatória e sistematicamente em cada secção para promover a análise morfométrica. A área teste utilizada neste trabalho foi de $0,04 \mathrm{~mm}^{2}$. Os neurônios contidos nesta área teste foram numerados individualmente, cada um recebendo um número no qual se repetia nas diferentes secções quando se tratava do mesmo perfil neuronal ${ }^{10,11}$. Nas secções onde o perfil neuronal era máximo, mensurou-se a área do corpo celular e os eixos maior e menor. A área do núcleo também foi mensurada na secção de perfil máximo. Os dados morfométricos foram obtidos e calculados com o auxílio do Programa para processamento e análise de imagens KS 400 Zeiss ${ }^{\circledR}$, devidamente calibrado . As imagens foram capturadas com o auxílio do microscópio Axioscópio Zeiss ${ }^{\circledR}$ (objetiva 20x) e de uma câmera TK-128OU JVC ${ }^{\circledR}$, na qual transferia a imagem para uma tela de computador.

\section{Estudo estereológico}

Densidade dos perfis neuronais NADPH-d positivos "packing density" ou "profile density" $\left(\mathrm{Q}_{\mathrm{A}}\right)$.

Expressa o número de perfis celulares por unidade de área (neste trabalho: neurônios NADPH-d positivos $/ \mu^{2}$ ). A densidade de perfis neuronais é obtida através da quantificação do número de perfis neuronais existentes dentro de uma área teste conhecida. Utilizando-se 20 secções seriadas de $30 \mu \mathrm{m}$ por gânglio obtidos no micrótomo de deslizamento, foram analisadas, aletória e sistematicamente, cinco diferentes regiões em cada secção, totalizando 100 áreas teste de análise por gânglio, correspondendo a 300 áreas por grupo. A área teste utilizada para a quantificação foi de $0,04 \mathrm{~mm}^{2}$.

\section{Fração de área dos neurônios NADPH-d positivos}

Os mesmos campos analisados para estimar a densidade dos perfis neuronais NADPH-d positivos foram usados para calcular a fração de área do gânglio celíaco ocupada pelos neurônios ganglionares NADPH-d positivos, isto é comumente determinado sobrepondo -se aleatoriamente 
um sistema teste de pontos sobre uma área de interesse, no nosso caso a secção contendo o tecido ganglionar ${ }^{12}$. Com o sistema teste sobreposto à área de interesse escolhida, são contados o total de pontos que tocam os perfis neuronais (Ó Pn) e também o total de pontos que tocam toda a área de interesse (área da secção ganglionar) (Ó Psg). Através da relação entre Ó Pn/ Ó Psg é obtida a fração de área dos neurônios NADPH-d positivos. Este parâmetro varia de zero a um, sendo freqüentemente expresso em porcentagem.

\section{Resultados}

\section{Macroestrutura}

O gânglio celíaco esquerdo foi identificado lateralmente e sobreposto à artéria celíaca e ventralmente à glândula adrenal esquerda. Foram utilizados Seis gânglios celíacos esquerdos provenientes de cães domésticos (canis familiares) adultos, fêmeas, sem raça definida (SRD). O formato do gânglio era irregular.

\section{Microestrutura}

O gânglio celíaco estava envolto por uma cápsula ganglionar conjuntiva que emitia septos denominados de septos intraganglionares para o interior do mesmo. Estes septos ramificavam-se em septos inter-unidades, determinando o arranjo espacial dos neurônios ganglionares em agrupamentos ou seja em unidades ganglionares, caracterizando um complexo ganglionar.

As unidades ganglionares eram compostas, no gânglio celíaco esquerdo de cães domésticos, pelos neurônios ganglionares, capilares intra-unidades e interunidades (Figuras 1 e 2).

\section{Morfometria}

Foram mensurados 141 neurônios provenientes dos gânglios celíacos esquerdos de cães domésticos. Nestes, a área seccional do corpo celular variou de 122,5 a 1834,7 $\mathrm{mm}^{2}$ (média $=781,3 \mathrm{~mm}^{2} ;$ desvio padrão $=307,1)$, sendo que $41,84 \%$ dos neurônios apresentaram uma área seccional entre 800-1200 um ${ }^{2}$ (Figura 3). O tamanho do núcleo neuronal foi verificado em 108 neurônios. Á área seccional nuclear variou de 12,4 a $231,5 \mathrm{~mm}^{2}$, sendo que em 49,1\% dos núcleos analisados uma área seccional entre 0 - $60 \mathrm{~mm}^{2}$ (média $=76,7 \mathrm{~mm}^{2}$; desvio padrão $=50)$. (Figura 4).

\section{Caracterização e distribuição dos neurônios NADPH-d positivos}

Os neurônios apresentavam o corpo celular elíptico, circular e triangular. Sendo que apenas um núcleo periférico foi constatado. Do ponto de vista qualitativo, observou-se variação na intensidade de coloração (azul escuro) no pericário dos animais estudados para a reação NADPHd. (Figura 5).

\section{Estudo estereológico}

Fração de área ocupada pelos neurônios reativos áo NADPH-d

A fração de área do gânglio celíaco ocupada pelos neurônios reativos ao NADPH-d, variou de $48 \%$ a $71 \%$ (média $=61 \%$; desvio padrão $=7,3$ )

Densidade de neurônios reativos á nadph-d "packing density" por área ganglionar

A densidade de perfis neuronais NADPH-d reativos variou de $24,5 \times 10^{-5} \mathrm{a}$ $36 \times 10^{-5}$ perfis $/ \mathrm{mm}^{2}$ (média $27,5 \times 10^{-5}$ perfis $/ \mathrm{mm}^{2}$; desvio padrão $\left.=3,3 \times 10^{-5}\right)$.

\section{Discussão}

\section{Aspectos Macroscópicos}

Reportou-se que macroscopicamente no antímero esquerdo, o gânglio celíaco esquerdo de ratos é formado por três principais componentes. 1 - o gânglio adrenal esquerdo em continuidade com o nervo celíaco esquerdo e com o nervo esplâncnico maior esquerdo, 2 - o gânglio celíaco esquerdo e 3 - o gânglio mesentérico cranial esquerdo, estes três componentes apresentavam-se fundidos e nas proximidades era possível 


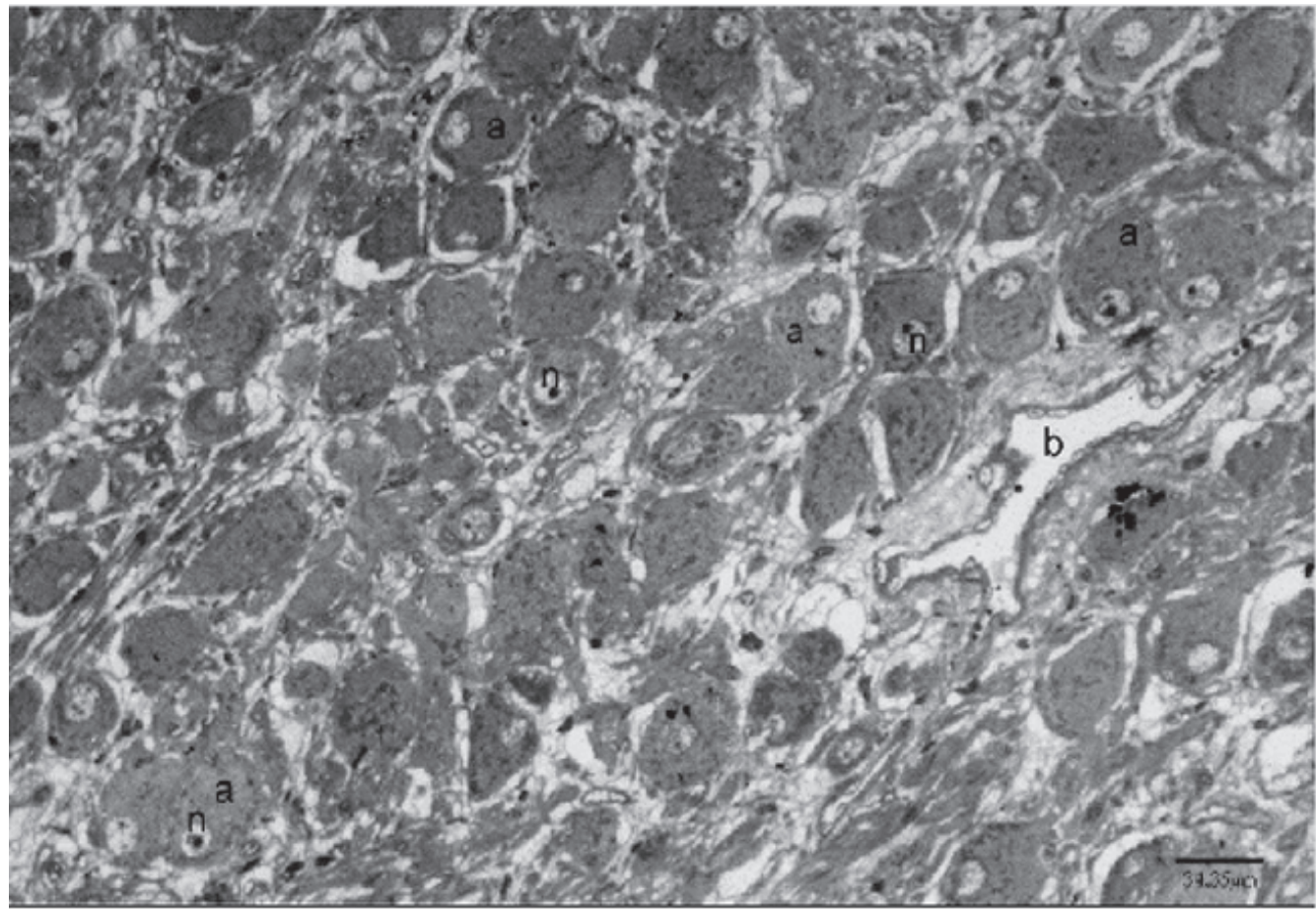

Figura 1 - Fotomicrografia exibindo a composição das unidades ganglionares no gânglio celíaco do cão. Identificando-se: a) neurônio ganglionar, b) capilares intra-unidades; n) núcleo do neurônio ganglionar. Escala debarra = 34,35 $\mu$ me Técnica de coloração - Azul de Toluidina

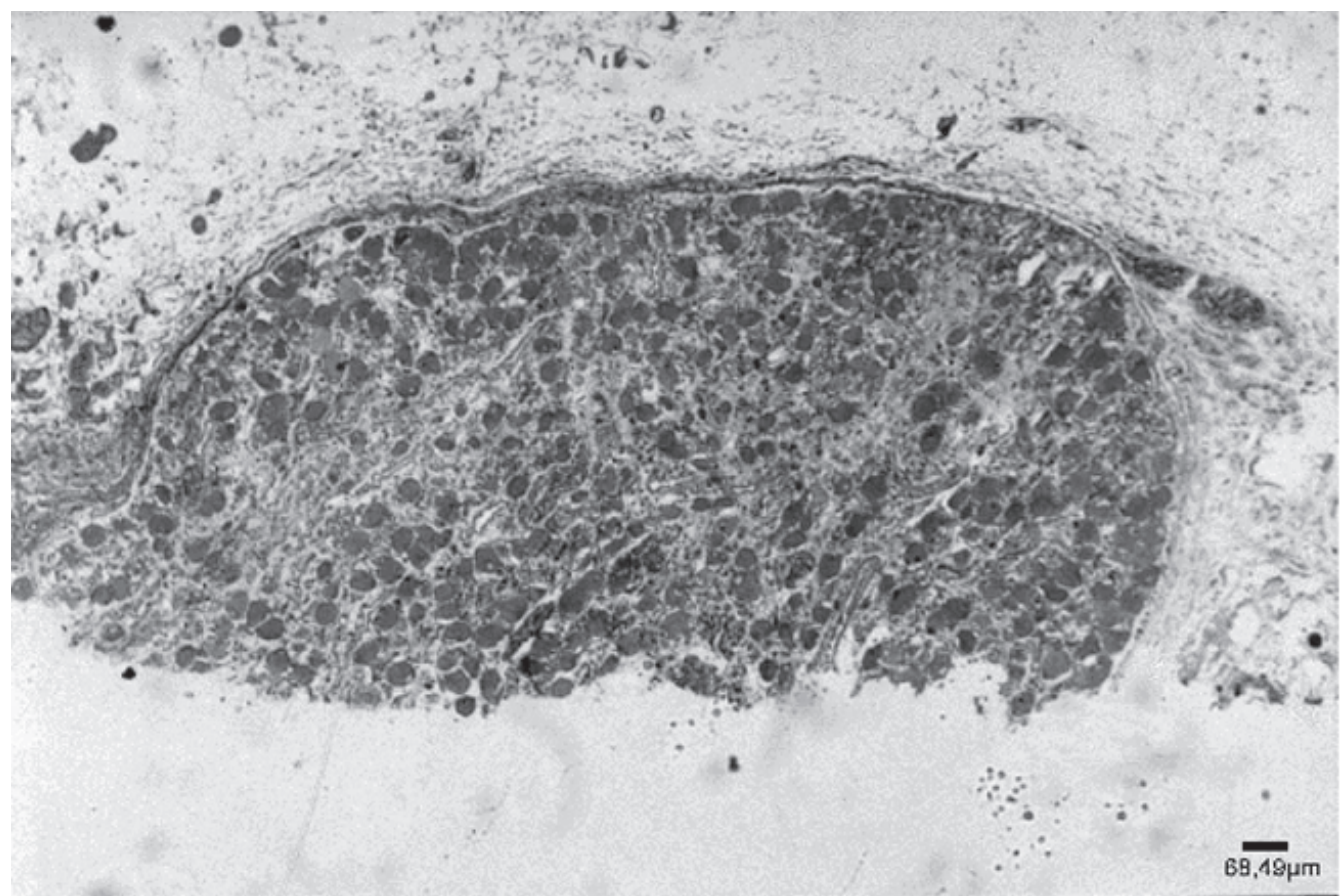

Figura 2 - Fotomicrografia exibindo o arranjo estrutural do complexo ganglionar celíaco do cão envolto por uma cápsula ganglionar conjuntiva. Escala de barra $=68,49 \mu$ m e Técnica de coloração - Azul de Toluidina 


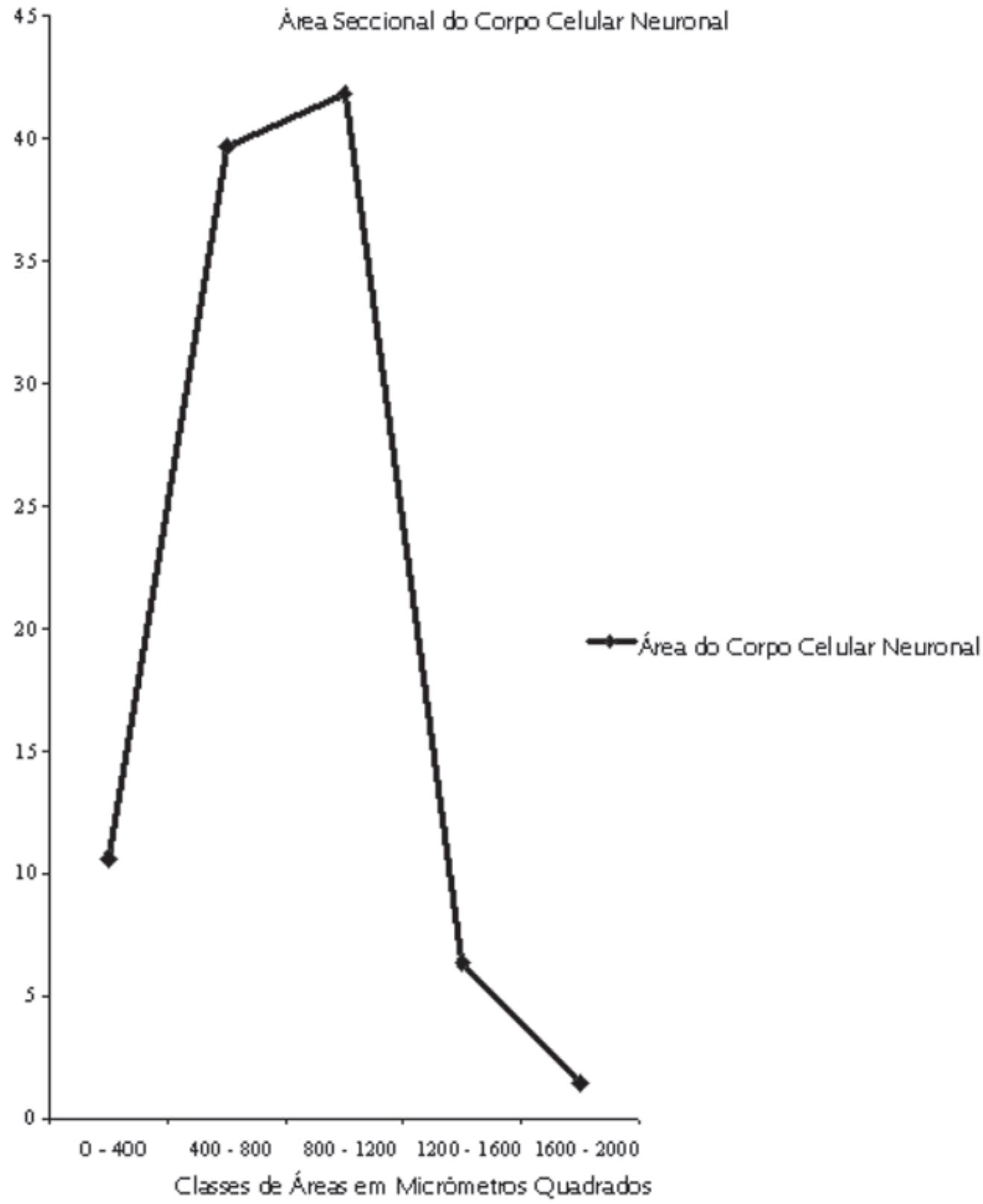

Figura 3 - Gráfico mostrando a distribuição da Área seccional do Corpo Celular Neuronal onde se observa cinco Classes de Áreas em Micrômetros Quadrados sendo a menor de $0-400 \mu \mathrm{m}^{2}$ e a maior $1600-2000 \mu \mathrm{m}^{2} \mathrm{e}$ as suas respectivas freqüências

identificar o gânglio aórtico-renal ${ }^{13}$.

No cavalo, revelou-se que o plexo celíaco-mesentérico e os gânglios celíaco esquerdo e mesentérico cranial podem estar variavelmente fusionados em uma massa difusa situada na parede dorsal da cavidade abdominal, circundando as origens das artérias celíaca e mesentérica cranial, sendo contínuos ao plexo mesentérico caudal ${ }^{2}$.

Quanto à forma do gânglio celíaco esquerdo de ratos, classificou-se de aspecto semi-lunar, localizando-se lateralmente a artéria celíaca e a artéria mesentérica cranial ${ }^{1}$. O gânglio celíaco e o gânglio 


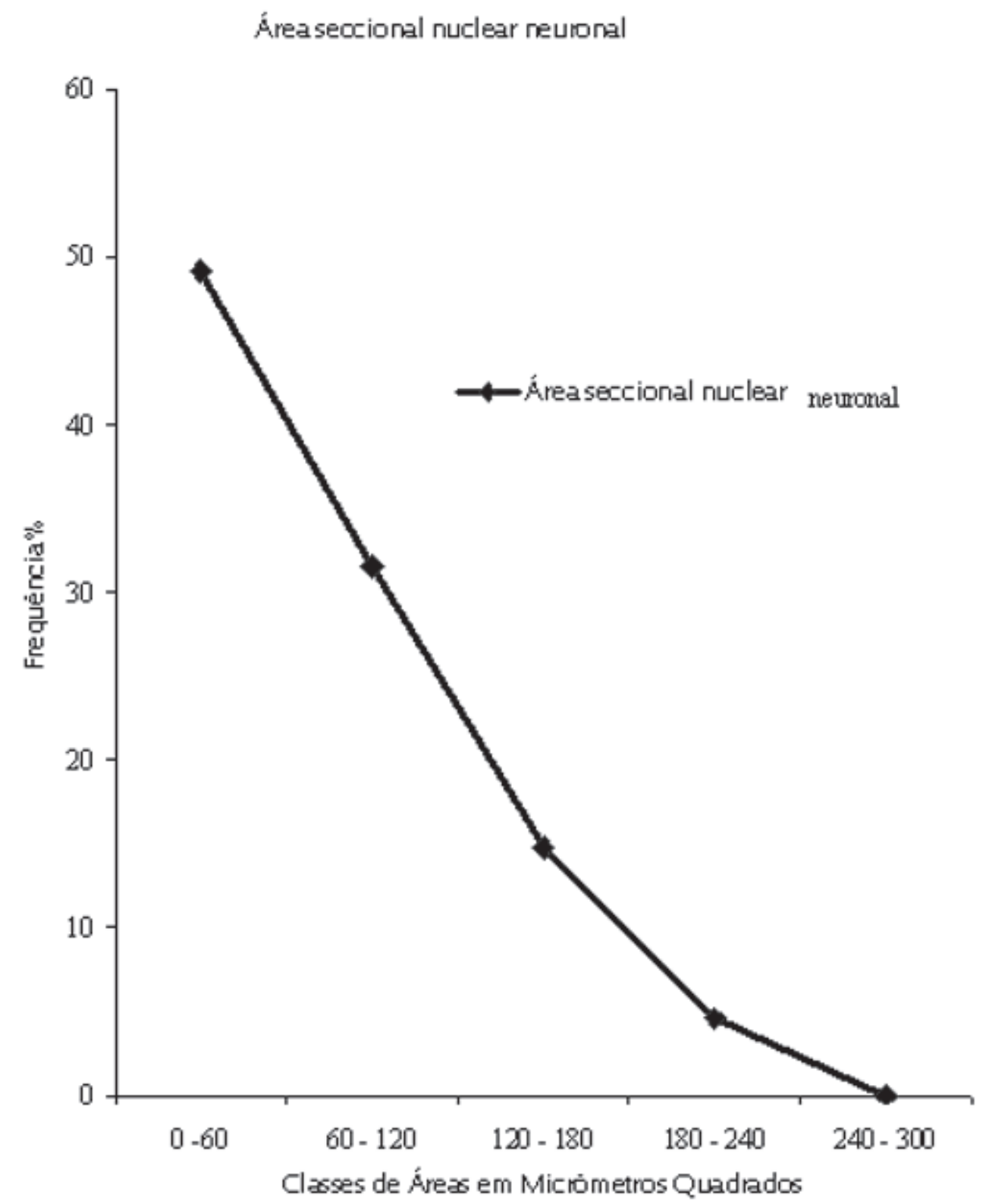

Figura 4 - Gráfico mostrando a distribuição da Área seccional nuclear neuronal onde se observa cinco classes de Áreas em micrômetros quadrados sendo a menor de $0-60 \mu \mathrm{m}^{2}$ e a maior $240-300 \mu \mathrm{m}^{2}$ e as suas respectivas freqüências

mesentérico cranial estão localizados em uma rede plexiforme no cão ${ }^{14}$. Apesar de em ambos os antímeros os gânglios celíacos receberem filamentos nervosos dos nervos vagos, o maior contingente provém do nervo vago direito. O plexo em volta da artéria hepática geralmente é formado pelo gânglio celíaco direito e nervo vago e emite feixes nervosos para o pâncreas e estômago ${ }^{4}$. Relataram-se que o complexo ganglionar celíaco tem sido descrito como um par de amplos gânglios pré-vertebrais de formato irregular que inclui o gânglio celíaco, gânglio mesentérico cranial, gânglio adrenal, gânglios aórtico-renais e 


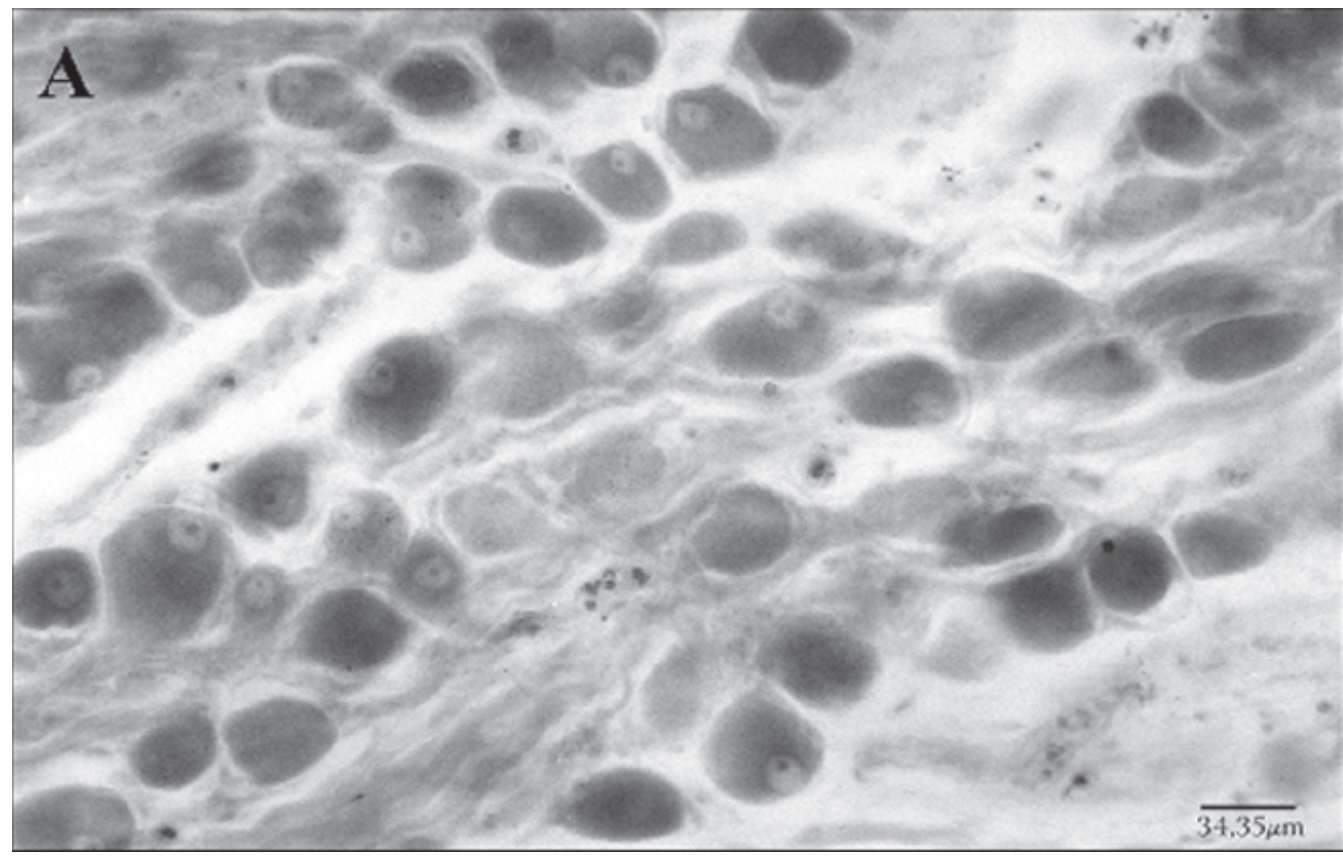

Figura 5 - Fotomicrografia do gânglio celíaco do cão mostrando neurônios NADPH-d positivos apresentando coloração intensa devido à reação positiva. Escala de barra de 34,35 mm. Reação da NADPH-diaphorase

seus plexos nervosos ${ }^{15}$.

Em nossos resultados, e de acordo com a literatura ${ }^{1,2}$, a localização do gânglio celíaco esquerdo ocorreu junto à origem da artéria celíaca com pequenas variações individuais. No entanto, diferente de outros relatos ${ }^{2}$, os gânglios celíaco esquerdo e mesentérico cranial de cães apresentavam-se individualizados em todos os casos. Quanto ao aspecto macroscópico do gânglio, ou seja, um formato irregular, nossos resultados aproximam-se daqueles da literatura ${ }^{15}$.

Em todos os animais observados, o gânglio celíaco estava isolado do gânglio mesentérico cranial, que se localizava junto à origem da artéria homônima e portanto caudalmente ao gânglio celíaco esquerdo.

\section{Aspectos microscópicos Microestrutura geral}

Relatou-se que uma cápsula colágena envolve o gânglio cervical cranial e o gânglio mesentérico cranial em humanos, sendo que ocasionalmente emite septos para o interior do mesmo conferindo-lhe uma apresentação nodular e, mais particularmente, isto ocorre no gânglio mesentérico $\mathrm{cranial}^{16}$.
À microscopia de luz, verificaram que o gânglio mesentérico cranial de camundongo era envolvido por uma tênue cápsula. O parênquima ganglionar contúnha densos conjuntos de corpos neuronais e células satélites, sendo os neurônios geralmente ovais e facilmente identificados pelos seus núcleos únicos, periféricos, arredondados e contendo de um a dois nucléolos. As células satélites foram reconhecidas por sua densa coloração e menor tamanho. O neurópilo ganglionar continha muitos vasos, sendo também, observados mastócitos e células SGC - "small granule containing"

Quanto à vasculatura ganglionar, relataram-se que nos gânglios simpáticos de ratos, dois tipos de vasos tem sido caracterizados: capilares contínuos adjacentes aos neurônios ganglionares e capilares fenestrados localizados próximos às pequenas células contendo grânulos (SGC) 17,18,19,20. Em nossos estudos também foram observados os capilares próximos a neurônios que foram denominados de capilares intra-unidades, porém estes não foram avaliados quanto à sua característica de fenestração ou de continuidade. 
Quanto à presença de uma cápsula ganglionar, nossos resultados concordam com os relatos da literatura ${ }^{16}$, embora este último estudou os gânglios cervical cranial e mesentérico cranial. A ocorrência de septos capsulares direcionados para o interior do gânglio celíaco conferindo-lhe aspecto nodular e dividindo o parênquima em grupos de neurônios ou unidades ganglionares, também foi observado, no gânglio celíaco de cães. No entanto, não identificamos a existência de fibras colagenas na estrutura capsular com os métodos de coloração empregados. As unidades ganglionares eram compostas por neurônios ganglionares com um núcleo periférico e um nucléolo, células da glia e capilares intraunidades. os capilares ganglionares puderam ser observados ao longo de todo o complexo ganglionar celíaco dispostos nos septos conjuntivos intraganglionares capilares inter-unidades e no interior das unidades - capilares intra-unidades em acordo com a literatura ${ }^{17,18,19,20,21}$. A estrutura geral do gânglio celíaco de cães domésticos,tanto em relação aos tipos celulares encontrados quanto a organização do parênquima em unidades ganglionares, estão em acordo com as observações de um único artigo citado na literatura ${ }^{22}$.

\section{Aspectos Morfométricos}

O tamanho do corpo celular de 141 neurônios do gânglio celíaco esquerdo de cães, representado pela sua área seccional foi em média de $781 \mathrm{~mm}^{2}$, também foi reportado na literatura ${ }^{23}$ para os neurônios do gânglio mesentérico inferior de rato que se projetam para a bexiga urinária uma área média de $221 \mathrm{~mm}^{2}$ e para neurônios do gânglio mesentérico inferior que se projetam para o cólon uma área média de $351 \mathrm{~mm}^{2}$. Da mesma forma foi observado na literatura ${ }^{5}$ para o gânglio mesentérico superior de camundongo nas suas porções caudal, média e cranial uma área média de $400 \mathrm{~mm}^{2}$, $435 \mathrm{~mm}^{2}, 484 \mathrm{~mm}^{2}$, respectivamente. Também foi visto na literatura ${ }^{24}$ no gânglio mesentérico superior de mulheres jovens $(<65$ anos $)$ e velhas ( $=70$ anos $)$ uma área média de $1648 \mathrm{~mm}^{2}$ e $1686 \mathrm{~mm}^{2}$, respectivamente.

\section{Neurônios NADPH-diaphorase reativos}

Muitos autores têm reportado que a NADPH-diaphorase age como co-enzima na síntese de NO - "nitric oxide" além da participação de outras enzimas como a arginia e a molécula de oxigênio. Nos tecidos nervosos, em especial em gânglios autônomos a NADPH-d pode também estar relacionada com a expressão da NOS "nitric oxide synthase" detectada imunohistoquímicamente nos mesmos neurônios ${ }^{25,26,27,28,29,30}$.

Mostrou-se que nos gânglios paravertebrais a maioria dos pericários dos neurônios simpáticos apresentavam reação discreta e homogênea ao produto da reação da NADPH-d, já os neurônios dos gânglios pré-vertebrais demonstraram intensa reação ao NADPH-d ${ }^{31}$. Os autores também observaram que os neurônios ganglionares do complexo celíaco-mesentérico eram circundados por desde simples fibras reativas até por densas aglomerações de fibras reativas à NADPH-diaphorase

No presente estudo, embora não estudamos o caráter destas fibras reativas a NADPH - d, a reatividade à esta enzima foi intensa, sendo que em média $61 \%$ da área do gânglio celíaco era ocupada por neurônios NADPH - $\mathrm{d}$ reativos.

Estudos histoquímicos e imunohistoquímicos têm ajudado a descrever a ação da NO "nitric oxide" como um neurotransmissor no sistema nervoso periférico e central por meio da identificação da atividade da NADPHdiaphorase, além da própria identificação da NOS "nitric oxide synthase". Estes estudos têm demonstrado que populações de neurônios no gânglio celíaco-mesentérico de ratos e de cobaias são circundados por fibras nervosas reativas à NOS ${ }^{31,32,33}$.

Portanto estes autores fundamentam que a expressão tanto da NADPHdiaphorase quanto da NOS conferem característica potencialmente nitrérgica, ou 
seja, potencial para a produção de óxido nítrico por estes neurônios.

$\mathrm{Na}$ presente investigação foram encontrados neurônios NADPH-diaphorase reativos, apresentando reação visível, intensa e homogênea. A identificação e a quantificação desta reatividade permitiu-nos concluir que há neurônios potencialmente nitrérgicos no gânglio celíaco de cães domésticos. No entanto, não podemos afirmar que estes neurônios sejam efetivamente nitrérgicos, porque tal constatação exige a combinação de outras reações imunohistoquímicas como a NOS e a nitrotirosina , que identifica "nitrosylate proteins" que são mais acuradamente representativas da atividade do óxido nítrico nestas células nervosas.

\section{Agradecimento}

À Professora Dra. Carol Fuzeti Elias por ter disponibilizado o seu laboratório de neuroanatomia química no Departamento de Anatomia do Instituto de Ciência Biomédicas III da Universidade de São Paulo

\title{
Morphometric and stereological study of the celiac ganglia in healthy dogs
}

\begin{abstract}
In this research, the macrostructural, microstructural and histochemical aspects wereInvestigated in 6 clinacally health dogs to identify thepossible alterations on the strucutre, morphometric and qualitative parameteres ofneurons of the celiac ganglionar complex. Our observations revealed that the celiacganglion was originated dose to the origin of the celiac artery and showed a irregularaspect, being caractherized as a complex. Histochemical/y, neurons NADPHdiaphorase reactives were identified. This positive reaction, on health animais, led us to conclude this neurons were potentially nitrergic, besides, to confirm the nitrergic aspect for this neurons it is necessary to combineimmunohistochemical method.
\end{abstract}

Key-words: Ganglion.

\section{Referências}

1 GABELLA, G. The rat autonomic nervous system. London: Academic Press, 1995, p. 81-93.

2 GHOSHAL, N. G. Inervação autônoma abdominal, pélvica e caudal. In:__ Sisson e Grossman anatomia dos animais domésticos Getty, R. Ed. Guanabara Koogan, 5. ed., 1986, p. 650-654.

3 LÉRÁNTH, C.; UNGVÁRY, G. Axon types of prevertebral ganglia and the peripheral autonomic reflex arc. J. Auton. Nerv. Syst., v. 1, n. 3, p. 265-281, 1980.

4 BARON, R.; JANIG, W. Sympathetic and afferent neurons projecting in the splenic nerve of the cat. Neurosci, Lett., v. 94, n.1,2, p. 109-113, 1988.

5 MILLER, S. M.; HANANI, M.; KUNTZ, S. M.; SCHMALZ, P. F.; SZURSZEWSKI, J. H. Light, electron and confocal microscopic study of the mouse superior mesenteric ganglion. J. Comp. Neurol, v. 365, n.3, p.
427-444, 1996.

6 SCHERER-SINGLER, U.; VINCENT, S. R.; KIMURA, H.; MCGEER, E. G. Demosntration of a unique population of neurosn with NADPH-diaphorese histochemistry. J. Neurosci. Method., v. 9, n. 3, p. 229-234, 1983.

7 ATOJI, Y.; MIZUTANI, K.; YAMAMOTO, Y.; SUZUKI, Y. Innervation of the pigeon oviduct: correlation of NADPH diaphorese with acetylcholinesterase, tyrosine hydroxylase and neuropeptides. Auton. Neurosci.: basic and clinical, v. 84, n.1,2, p. 1-7, 2000.

8 GUNDERSEN, H. J. C. Notes on the estimation of the numerical density of arbitrary profiles: the edge effect. J Microsc., v. 111, p. 219-223, 1977.

9 HOWARD, C.V; REID S, BADDELEY A; BOYDE A. Unbiased estimation of particle density in the tandem scanning reflected light microscope. J Microsc. , v. 138, n.2, p. 203-212, 1985. 
10 GABELLA, G.; TRIGG, P.; MCPHAIL, H. Quantitative cytology of ganglion neurons and satellite glial cells in the superior cervical ganglion of the sheep. Relationship with ganglion neuron size. J. Neurocytol., v. 17, n. 6 , p. $753-769,1988$.

11 GABELLA, G.; BERGGREM, T.; UVELIUS, B. Hypertrophy and reversal hypertrophy in rat pelvic ganglion neurons. J. Neurocytol., v. 21, n. 9, p. 649662, 1992.

12 HOWARD C. V.; REED, M. G. Unbiased Stereology. Three Dimensional measurement in Microscopy. BIOS Scientific Publishers, p. 246, 1998.

13 HAMMER, D. W.; SANTER, R. M. Anatomy and blood supply of celiac-superior mesenteric ganglion complex of the rat. Anat. Embryol. (Berl.), v. 162, p. 353-362, 1981.

14 MIZERES,N.J; : The anatomy of the autonomic nervous system in the dog. Am.J. Anat. v. 96, p. 258318, 1955

15 PROMWIKORN, W.; THONGPILA, S.; PRADIDARCHEEP, W.; MINGSAKUL, T.; CHUNHABUNDIT, P.; SOMANA, R. Angioarchitecture of the celiac sympathetic ganglion complex in the common tree shrew (Tupaia glis). J. Anat., v. 193, n. 3, p. 409-416, 1998.

16 SCHMIDT, R. E. The neuropathology of human sympathetic autonomic ganglia. Microcosp. Res. Tech., v. 35, n. 2 , p. 107-121, 1996.

17 DEPACE, D. M. Morphologic study of the blood vessels of the superior cervical ganglion of the albino rat. Acta Anat; v. 109, p.3, p. 238-246, 1981.

18 ABE, H.; WATANABE, H.; YAMAMOTO, T.Y. Relationship between granule-containing cells and blood vessels in the rat autonomic ganglia. Anat. Rec., v. 205 , n. 1, p. 65-72, 1983.

19 CHAU, Y. P.; CHIEN, C. L.; LU, K. S. The permeability of capillary among the small granulecontaining cells in rat superior cervical ganglia: An ultrastructural lanthanum tracer study. Histol. Histopathol., v. 6, p.2, p. 261-268, 1991.

$20 \mathrm{CHAU}$, Y. P.; LU, K. S. Investigation of the bloodganglion barrier properties in rat sympathetic ganglia by using lanthanum ion and horseradish peroxidase as tracers. Acta Anat., v. 153, n. 2, p. 135-144, 1995.

21 MASCORRO, J. A.; BREAUX, T. F.; and YATES, R. D. Morphological observations of small granule containing (chromaffin) cells in the celiac ganglion of the guinea-pig, with emphasis on cell contacts. Microscop. Res. Tech., v. 29, n. 2, p. 169-176, 1994.

22 RIBEIRO AACM, ELIAS CF, LIBERTI EA, GUIDI WL, DE SOUZA RR. Structure and ultrastructure of the celiac-mesenteric ganglion complex in the domestic dog (Canis familiaris ). Anat. Histol Embryol. v. 31, n. 6, p. 344-349, 2002
23 NADELHAFT I. ; VERA P.L. ; STEINBACHER B. Hypertrophic neurons innervating the urinary bladder and colon of the streptozotocin-diabetic rat. Brain Res., v. 609 , n. 1,2, p. $277-283,1993$

24 SCHMIDT R. E. ; PLURAD S. B. ; PARVIN C. A. ; ROTH K. A. Effect of diabetes and aging on human sympathetic autononomic ganglia. Am. J. of Pathol., v. 143, n. 1, p. 143-153, 1993.

25 MARLETTA, M. A. Nitric oxide: biosynthesis and biological significance. Trends. Biochem. Sci., v. 14, n. 1,2, p. 488-492, 1989.

26 FÖRSTEMANN, U.; SCHMIDT, H. H. H. W.; POLLOCK, J. S.; SHENG, H.; MITCHELL, J. A.; WARNER, T. D.; NAKANE, M.; MURAD,F. Isoforms of nitric oxide synthase. Characterization and purification from different cell types. Biochem. Pharmacol., v. 42, n. 10, p. 1849-1857, 1991.

27 HOPE, B. T.; MICHAEL, G. J.; KNIGEE, K. M.; VINCENT, S. R. Neuronal NADPH-diaphorese is a nitric oxide synthase. v. 88, n. 7, p.2811-2814, 1991

28 VINCENT, S. R. and HOPE, B. T. Neurons that say NO. Trends Neurosci., v. 15, n. 3, p. 108-113, 1992.

29 BREDT, D. S.; SNYDER, S. H. Nitric oxide, a novel neuronal messenger. Neuron, v. 8, n. 1, p. 3-11, 1992.

30 MARLETTA, M. A. Nitric oxide synthase structure and mechanism. J. Biol. Chem., v. 268, n. 17, p. 1223112234, 1993.

31 SANTER, R. M.; SYMONS, D. Distribution of NADPH-diaphorese activity in rat paravertebral, prevertebral and pelvic sympathetic ganglia. Cell Tissue Res., v. 271, n.1, p. 115-121, 1993.

32 ANDERSON, C. R.; EDWARDS, S. L.; FURNESS, J. B.; BREDT, D. S.; SNYDER, S. H. The distribution of nitric oxide synthase-containing autonomic preganglionic terminals in the rat. Brain Res., v. 614, n. 1,2, p. 78-85, 1993.

33 FURNESS, J. B.; ANDERSON, C. R. Origins of nerve terminals containing nitric oxide synthase in the guineapig celiac ganglion. J. Auton. Nerv. Syst., v. 46, n. 1,2, p. 47-54, 1993. 